\title{
Níveis de água, nitrogênio e potássio por gotejamento subsuperficial em cana-de-açúcar
}

\author{
Aderson Soares de Andrade Júnior(1), Edson Alves Bastos(1), Valdenir Queiroz Ribeiro(1), \\ José Adilberto Lemos Duarte ${ }^{(2)}$, Darlan Leão Braga ${ }^{(3)}$ e Donavan Holanda Noleto(4)
}

\begin{abstract}
(1)Embrapa Meio-Norte, Avenida Duque de Caxias, no 5.650, Bairro Buenos Aires, CEP 64006-220 Teresina, PI. E-mail: aderson@cpamn.embrapa.br, edson@cpamn.embrapa.br, valdenir@cpamn.embrapa.br (2)Universidade Federal do Piauí (UFPI), Centro de Ciências Agrárias, Programa de Pós-Graduação em Agronomia, Campus Socopo, CEP 64049-550 Teresina, PI. E-mail: adilberto@cpamn.embrapa.br (3)Universidade Federal do Ceará, Centro de Ciências Agrárias, Departamento de Engenharia Agrícola, Caixa Postal 12.168, CEP 60450-760 Fortaleza, CE. E-mail: darlanlb@hotmail.com ${ }^{(4)}$ UFPI, Centro de Ciências Agrárias, Curso de Agronomia. E-mail: donavanoleto@yahoo.com.br
\end{abstract}

Resumo - O objetivo deste trabalho foi definir os níveis ótimos de irrigação, nitrogênio e potássio em cana-de-açúcar, cultivar RB867515, aplicados por gotejamento subsuperficial, em ciclo de primeira soca, para máxima produção de colmos, açúcar e álcool. O experimento foi realizado em Plintossolo do Município de União, no Estado do Piauí, durante o ano agrícola 2008/2009. Os tratamentos consistiram de: níveis de irrigação mais precipitação (W1, 767,5; W2, 898,5; W3, 971,0; W4, 1.053,0; e W5, 1.154,0 mm) e níveis de adubação nitrogenada e potássica $(\mathrm{N} 1,44,0 ; \mathrm{N} 2,78,0 ; \mathrm{N} 3,111,0 ; \mathrm{N} 4,144,0 ; \mathrm{N} 5,178,0 ; \mathrm{K} 1,44,0$; K2, 67,0; K3, 89,0; K4, 111,0; e K5, 133,0 kg ha-1 $)$. Utilizou-se o delineamento experimental de blocos ao acaso, com duas repetições, em arranjo fatorial fracionário $1 / 5$ de $5 \times 5 \times 5(\mathrm{~W} \times \mathrm{N} \times \mathrm{K})$. A produtividade máxima de colmos (207,4 $\left.\mathrm{Mg} \mathrm{ha}^{-1}\right)$ é alcançada com a aplicação de 1.154,0 mm de água, associada a 114,2 $\mathrm{kg} \mathrm{ha}^{-1}$ de N e $60,1 \mathrm{~kg} \mathrm{ha}^{-1}$ de $\mathrm{K}_{2} \mathrm{O}$. A máxima produtividade de açúcar $\left(25,3 \mathrm{Mg} \mathrm{ha}^{-1}\right)$ e de álcool $\left(20,0 \mathrm{~m}^{3} \mathrm{ha}^{-1}\right)$ é obtida com $1.154,0 \mathrm{~mm}$, associada à aplicação dos níveis de $90,0 \mathrm{~kg} \mathrm{ha}^{-1}$ de $\mathrm{N}$ e de $60,0 \mathrm{~kg} \mathrm{ha}^{-1}$ de $\mathrm{K}_{2} \mathrm{O}$.

Termos para indexação: Saccharum officinarum, agroenergia, irrigação.

\section{Irrigation, nitrogen and potassium levels under subsurface drip on sugarcane}

\begin{abstract}
The objective of this work was to define the optimal irrigation, nitrogen and potassium levels in sugarcane, cultivar RB867515, applied by subsurface drip, in the first ratoon, to maximize stem, sugar and alcohol yield. The experiment was carried out on Plinthaquox soil in the county União, Piauí State, Brazil, during the 2008/2009 agricultural season. The treatments consisted of: irrigation levels including rainfall (W1, 767.5; W2, 898.5; W3, 971.0; W4, 1,053.0; and W5, 1,154.0 mm) and nitrogen and potassium levels (N1, 44.0; $\mathrm{N} 2,78.0 ; \mathrm{N} 3,111.0 ; \mathrm{N} 4,144.0 ; \mathrm{N} 5,178.0 ; \mathrm{K} 1,44.0 ; \mathrm{K} 2,67.0 ; \mathrm{K} 3,89.0 ; \mathrm{K} 4,111.0$; and K5, $\left.133.0 \mathrm{~kg} \mathrm{ha}^{-1}\right)$. The experimental design used was a randomized complete block with two replicates, in a $5 \times 5 \times 5$ (W x N x K) $1 / 5$ fractional factorial arrangement. Maximum stem yield $\left(207.4 \mathrm{Mg} \mathrm{ha}^{-1}\right)$ is reached with $1,154.0 \mathrm{~mm}$ of water associated with $114.2 \mathrm{~kg} \mathrm{ha}^{-1}$ of N and $60.1 \mathrm{~kg} \mathrm{ha}^{-1}$ of $\mathrm{K}_{2} \mathrm{O}$. Maximum sugar $\left(25.3 \mathrm{Mg} \mathrm{ha}^{-1}\right)$ and alcohol $\left(20.0 \mathrm{~m}^{3}\right.$ $\mathrm{ha}^{-1}$ ) yield is achieved with 1,154.0 mm associated with levels of $90.0 \mathrm{~kg} \mathrm{ha}^{-1}$ of $\mathrm{N}$ and $60.0 \mathrm{~kg} \mathrm{ha}^{-1}$ of $\mathrm{K}_{2} \mathrm{O}$.
\end{abstract}

Index terms: Saccharum officinarum, agroenergy, irrigation.

\section{Introdução}

O Brasil é o maior produtor mundial de cana-deaçúcar(Saccharum officinarum L.). Na safra 2010/2011, a região Nordeste contribuiu com o equivalente a $7 \%$ do total de 27,595 bilhões de litros de etanol por ano e com $12,0 \%$ do total de 38,168 milhões de toneladas de açúcar por ano produzidos pelo país (Companhia Nacional de Abastecimento, 2011). A baixa participação da região na produção nacional indica que há carência de aporte tecnológico, que aumente a produtividade da cultura da cana-de-açúcar, para que o setor sucroalcooleiro possa atender às crescentes necessidades do mercado agroenergético.

A estimativa de um crescimento superior a $50 \%$ na produção de cana-de-açúcar, até 2013, em resposta à demanda nacional e mundial por álcool combustível e açúcar (Ministério da Agricultura, Pecuária e Abastecimento, 2005), aponta para a necessidade de aumento da área plantada com a cultura no Brasil e de aumento de produção por área, nas regiões tradicionais de cultivo.

Os Estados do Tocantins, do Maranhão e do Piauí apresentam as áreas mais promissoras para essa 
expansão, com disponibilidade de 1.731.097,41 ha com aptidão ao cultivo da cana-de-açúcar, o que é atribuído às suas características de solo e clima (Manzatto et al., 2009). Contudo, nesses estados, as áreas potenciais para o cultivo da cana-de-açúcar situam-se em regiões com regime climático semiárido e subúmido seco, com precipitação pluvial insuficiente (de 800 a $1.200 \mathrm{~mm}$ anuais) (Andrade Júnior et al., 2004), e que não satisfazem às exigências hídricas da cultura de forma adequada durante todo o seu ciclo, o que requer a adoção da prática da irrigação.

A irrigação e a fertirrigação são técnicas benéficas para a cultura da cana-de-açúcar, pois proporcionam melhor desenvolvimento das plantas, maior produtividade e um produto de melhor qualidade. O gotejamento subsuperficial, em termos comparativos, tem-se destacado, notadamente, por apresentar inúmeras vantagens, tais como: redução da evaporação da água, redução de danos mecânicos ao sistema, menor interferência com os tratos culturais, melhor eficiência na aplicação dos fertilizantes dissolvidos na própria água de irrigação ou fertirrigação e aumento da longevidade do canavial.

Pesquisas, em várias regiões produtoras do mundo e do Brasil, com algumas variedades de cana-de-açúcar, têm mostrado o efeito da irrigação no aumento da produtividade, tanto de colmos como de açúcar. No Brasil, alguns estudos recentes foram conduzidos para avaliar a técnica da irrigação na cultura da cana-de-açúcar em diferentes ambientes de produção (Dalri \& Cruz, 2002; Dantas Neto et al., 2006; Farias et al., 2008). No entanto, cabe ressaltar que, em virtude das variações de solo, clima e genótipos avaliados, difere a recomendação dos níveis de disponibilidade de água no solo a serem mantidos, para obtenção de produtividades elevadas de açúcar e álcool. Portanto, é necessária a condução de outros experimentos, nos diferentes ambientes de produção do país (Dalri \& Cruz, 2008; Dalri et al., 2008; Carvalho et al., 2009).

O conhecimento do efeito das doses de nutrientes que maximizam a produtividade econômica da cultura, principalmente o nitrogênio e o potássio, baseia-se na adubação convencional via solo. A fertirrigação, embora seja uma técnica com elevado potencial para aumento da eficiência e redução dos custos da adubação, tem sido pouco praticada. Assim, estudos de doses e do fracionamento da aplicação necessitam ser executados nas regiões produtoras de cana.

O objetivo deste trabalho foi definir os níveis ótimos de irrigação, nitrogênio e potássio em cana-de-açúcar, cultivar RB867515, aplicados por gotejamento subsuperficial, em ciclo de primeira soca, para a máxima produção de colmos, açúcar e álcool.

\section{Material e Métodos}

O experimento foi conduzido em área pertencente à Usina COMVAP - Açúcar e Álcool Ltda., situada no Município de União, PI (4²51'15"S e $42^{\circ} 53^{\prime} 15^{\prime \prime} \mathrm{W}$, a $55 \mathrm{~m}$ de altitude), microrregião de Teresina, durante o ano agrícola de 2008/2009.

A variedade avaliada foi a RB867515, ciclo de primeira soca, que tem sido a mais recomendada para cultivo irrigado, tendo-se utilizado o espaçamento de plantio em fileira dupla de $1,3 \times 0,5 \times 1,8 \mathrm{~m}$. O ciclo de cultivo teve início em 19/6/2008, com o corte da cana-planta, e a colheita foi realizada no período de 29/6/2009 a 7/7/2009, quando a cultura encontravase com 378 dias após o primeiro corte e 322 dias após o pleno estabelecimento da rebrota dos colmos. O período de aplicação dos tratamentos de irrigação e fertirrigação foi de 8/8/2008 a 20/2/2009, o que totalizou 196 dias.

O solo da área experimental foi previamente classificado como Plintossolo (Santos et al., 2006), de textura média a argilosa e de média fertilidade natural, cujas características químicas e físico-hídricas estão descritas nas Tabelas 1 e 2, respectivamente.

O clima da região, segundo Thornthwaite \& Mather (1955), é subúmido seco, com moderado excedente hídrico no verão e elevada deficiência hídrica de julho a dezembro. As variáveis climáticas são: temperatura média do ar de $28,4^{\circ} \mathrm{C}$, umidade relativa do ar de $72,6 \%$, velocidade do vento de $1,1 \mathrm{~m} \mathrm{~s}^{-1}$, insolação média de 8,2 horas e precipitação pluvial de 1.336,5 mm (Bastos et al., 2008).

Os níveis de água foram definidos como um percentual da evapotranspiração de referência (ETo), estimada pelo método de Penman \& Monteith, em escala diária de tempo, com dados climáticos de estação agrometeorológica instalada a $500 \mathrm{~m}$ da área experimental, equipada com sistema de transmissão de dados via modem celular. Os tratamentos de níveis de 
água foram: W1, 40\% ETo; W2, 60\% ETo; W3, 80\% ETo; W4, 100\% ETo; e W5, 120\% ETo.

Os níveis de adubação nitrogenada e potássica avaliados foram definidos como um percentual das respectivas doses recomendadas em função da análise do solo (DAS), para um potencial de produção de 100 $\mathrm{Mg} \mathrm{ha}^{-1}$. Os níveis de nutrientes aplicados foram os seguintes: N1, 40\% DAS; N2, 70\% DAS; N3, 100\% DAS; N4, 130\% DAS; N5, 160\% DAS; K1, 40\% DAS; K2, 60\% DAS; K3, 80\% DAS; K4, 100\% DAS; e K5, 120\% DAS. A aplicação dos níveis de $\mathrm{N}_{\text {e }} \mathrm{K}_{2} \mathrm{O}$ foi efetuada por meio de fertirrigação, com uso de injetor hidráulico de deslocamento positivo, e a ureia e o cloreto de potássio (branco) foram as fontes de $\mathrm{N}$ e $\mathrm{K}_{2} \mathrm{O}$, respectivamente. As doses aplicadas foram superiores às previstas, pois admitiu-se eficiência de irrigação de $90 \%$, o que aumenta em aproximadamente $10 \%$ as doses aplicadas ao solo.

A fertirrigação foi aplicada com a mesma frequência da irrigação, porém, com uso de combinação diferente de fertilizantes, para não provocar incompatibilidade entre os produtos utilizados. O parcelamento das doses de nutrientes estabelecidas para cada tratamento foi realizado com a distribuição mensal de: N - 20\% (do terceiro ao sexto mês após a rebrota) e 10\% (no sétimo e no oitavo mês após a rebrota); e $\mathrm{K}_{2} \mathrm{O}-10 \%$ (no terceiro e no quarto mês após a rebrota) e $20 \%$ (do quinto ao oitavo mês após a rebrota). $\mathrm{O}$ fósforo foi aplicado mensalmente via fertirrigação na forma de MAP, bem como os micronutrientes.

Utilizou-se o sistema de irrigação por gotejamento subsuperficial, com os gotejadores incorporados na linha lateral e espaçados a cada $0,50 \mathrm{~m}$, os quais foram enterrados a uma profundidade de $0,25 \mathrm{~m}$ no solo. A diferenciação dos tratamentos de água ocorreu em tempos diferentes de irrigação, em função das frações de ETo equivalentes. A irrigação foi realizada sempre às segundas, às quartas e às sextas-feiras, tendo-se considerado a ETo acumulada entre as irrigações sucessivas. A precipitação, quando ocorreu, foi subtraída da lâmina de irrigação a ser aplicada. O controle de abertura e fechamento das parcelas no campo, para administração das lâminas de irrigação e para os níveis de $\mathrm{N}$ e $\mathrm{K}_{2} \mathrm{O}$, foi efetuado por válvulas hidráulicas instaladas em cavaletes nas entradas das parcelas, as quais foram manejadas a partir de um painel de controle na casa de bomba. A quantificação das lâminas aplicadas foi feita por hidrômetros instalados nas linhas de distribuição de irrigação de cada tratamento.

Os níveis de $\mathrm{N}, \mathrm{K}_{2} \mathrm{O}$ e irrigação aplicados durante os ciclos de produção da primeira soca da cana-de-açúcar estão descritos na Tabela 3. Utilizouse o delineamento experimental de blocos ao acaso, com duas repetições, em arranjo fatorial fracionário $1 / 5$ de $5 \times 5 \times 5$ (níveis de água $-\mathrm{W} \times$ doses de $\mathrm{N} \times$ doses de $\mathrm{K}_{2} \mathrm{O}$ ). Utilizou-se o teste $\mathrm{F}$ para testar a variância dos tratamentos, e a análise de regressão e de superfície de resposta para avaliação do efeito das interações $\mathrm{W} \times \mathrm{N} \times \mathrm{K}_{2} \mathrm{O}$. As parcelas foram constituídas de quatro fileiras duplas de plantio, com comprimento de $12 \mathrm{~m}$ e com área total de $86,4 \mathrm{~m}^{2}$. A área útil da parcela foi de $72,0 \mathrm{~m}^{2}$. As duas fileiras centrais apresentavam $10 \mathrm{~m}$ de comprimento cada

Tabela 1. Caracterização química do solo da área experimental.

\begin{tabular}{|c|c|c|c|c|c|c|c|c|c|c|c|c|c|}
\hline $\begin{array}{l}\text { Camada } \\
(\mathrm{m})\end{array}$ & $\begin{array}{c}\mathrm{pH} \\
\mathrm{em} \mathrm{H}_{2} \mathrm{O}\end{array}$ & $\begin{array}{c}\mathrm{MO} \\
\left(\mathrm{g} \mathrm{kg}^{-1}\right)\end{array}$ & $\begin{array}{c}\mathrm{P} \\
\left(\mathrm{mg} \mathrm{dm}^{-3}\right)\end{array}$ & K & $\mathrm{Ca}$ & $\mathrm{Mg}$ & $\begin{array}{r}\mathrm{Na} \\
--(\mathrm{cmc} \\
\end{array}$ & $\begin{array}{r}\mathrm{Al} \\
\left.\mathrm{dm}^{-3}\right) \\
\end{array}$ & $\mathrm{H}+\mathrm{Al}$ & $\mathrm{S}$ & CTC & V & m \\
\hline $0,00-0,20$ & 5,07 & 12,26 & 7,00 & 0,32 & 2,05 & 0,75 & 0,05 & 0,09 & 3,45 & 3,17 & 6,62 & 47,90 & 2,76 \\
\hline $0,20-0,50$ & 4,76 & 12,89 & 2,60 & 0,21 & 1,17 & 0,47 & 0,04 & 0,31 & 3,27 & 1,89 & 5,16 & 36,65 & 14,09 \\
\hline $0,50-1,25$ & 5,19 & 3,98 & 3,30 & 0,60 & 1,44 & 2,24 & 0,05 & 0,07 & 2,43 & 4,33 & 6,76 & 64,10 & 1,59 \\
\hline$>1,25$ & 5,11 & 5,17 & 1,60 & 0,17 & 0,27 & 0,72 & 0,09 & 0,22 & 1,40 & 1,25 & 2,65 & 47,13 & 14,97 \\
\hline
\end{tabular}

Tabela 2. Caracterização físico-hídrica do solo da área experimental ${ }^{(1)}$.

\begin{tabular}{|c|c|c|c|c|c|c|c|c|}
\hline \multirow{2}{*}{$\begin{array}{l}\text { Camada } \\
(\mathrm{m})\end{array}$} & \multicolumn{4}{|c|}{ Granulometria $\left(\mathrm{g} \mathrm{kg}^{-1}\right)$} & \multirow{2}{*}{\multicolumn{2}{|c|}{$\begin{array}{cc}\mathrm{CC} & \text { PMP } \\
----\left(\mathrm{m}^{3} \mathrm{~m}^{-3}\right) & - \\
\end{array}$}} & \multirow{2}{*}{$\begin{array}{c}\text { Ds } \\
\left(\mathrm{g} \mathrm{cm}^{-3}\right)\end{array}$} & \multirow{2}{*}{$\begin{array}{c}\text { Classificação } \\
\text { textural }\end{array}$} \\
\hline & Areia grossa & Areia fina & Silte & Argila & & & & \\
\hline $0,00-0,20$ & 140,0 & 542,0 & 212,0 & 106,0 & 24,30 & 9,87 & 1,53 & Franco-arenoso \\
\hline $0,20-0,50$ & 59,0 & 564,5 & 240,5 & 136,0 & 27,46 & 8,84 & 1,50 & Franco-arenoso \\
\hline $0,50-1,25$ & 24,0 & 369,5 & 300,5 & 306,0 & - & - & - & Franco-argiloso \\
\hline$>1,25$ & 7,0 & 723,0 & 174,0 & 96,0 & - & - & - & Franco-arenoso \\
\hline
\end{tabular}

${ }^{(1)} \mathrm{CC}$, capacidade de campo (10 kPa); PMP, ponto de murcha permanente $(1.500 \mathrm{kPa})$; Ds, densidade do solo. -, não analisado. 
uma, e a bordadura era constituída de uma fileira dupla de plantas de cada lado e de 1,0 m em cada extremidade da parcela. Quatro áreas com as mesmas dimensões de um bloco do experimento foram mantidas sem irrigação (testemunha relativa), e a cana foi adubada de acordo com a DAS para N, P e $\mathrm{K}_{2} \mathrm{O}$, com aplicação convencional no solo, conforme o sistema de produção da usina. Em cobertura, a testemunha recebeu, aos 60 dias após o corte, o equivalente a $500 \mathrm{~kg} \mathrm{ha}^{-1}$ da fórmula $\mathrm{N}-\mathrm{P}-\mathrm{K}$ 15-0-15 (166,7 kg ha-1 de ureia e $125,0 \mathrm{~kg} \mathrm{ha}^{-1} \mathrm{de}$ cloreto de potássio).

Ao final de cada ciclo produtivo da cana, determinouse a massa de matéria fresca do colmo e a percentagem de açúcar bruto, com os quais foi estimada a produção bruta de açúcar (PBA) e de álcool (PBAL), conforme as equações 1 e 2 (Caldas, 1998),

$\mathrm{PBA}=(\mathrm{PCC} \times \mathrm{PC}) \times 0,01$

$\mathrm{RBAL}=(((\mathrm{PCC} \times \mathrm{F})+\mathrm{ARL}) \times \mathrm{Fg}) \times 0,01 \times \mathrm{RC}$

em que: PCC é a percentagem de açúcar bruto (\%); $\mathrm{PC}$ é a produtividade de colmos $\left(\mathrm{Mg} \mathrm{ha}^{-1}\right)$; F é o fator de transformação estequiométrica de sacarose em uma molécula de glicose e em outra de frutose $(1,052)$; Fg é o fator de Gay Lussac $(0,6475)$; e ARL são os açúcares redutores livres (\%), cujos valores variam de 0,7 a $0,85 \%$, tendo-se utilizado o valor de ARL igual a 0,7 , para valores de PCC alto, de acordo com Carvalho et al. (2009).

Utilizou-se o programa estatístico SAS (SAS Institute, 2000) para as análises de variância dos dados. O programa computacional Table Curve 3D (Jandel Scientific, San Rafael, CA, EUA) foi utilizado para a obtenção das superfícies de resposta da produtividade de colmos, de açúcar e de álcool, em função dos níveis de irrigação, de nitrogênio e de potássio aplicados.

\section{Resultados e Discussão}

Foram observados valores de precipitação de $479,0 \mathrm{~mm}$ (Figura 1). No entanto, como os valores de precipitação foram reduzidos e espaçados, não houve prejuízos à condução normal do experimento. A precipitação após a suspensão da irrigação foi de $1.601,4 \mathrm{~mm}$. As lâminas de irrigação mais a precipitação registrada durante o período de aplicação dos tratamentos foram de: W1, 767,5 mm; W2, 898,5 mm; W3, 971,0 mm; W4, 1.053,0 mm; e W5, $1.154,0 \mathrm{~mm}$.

Uma vez que se admitiu eficiência de irrigação de $90 \%$, ocorreu aumento de aproximadamente $10 \%$ nas doses aplicadas ao solo. A variação nos níveis de irrigação, de $\mathrm{N}$ e de $\mathrm{K}_{2} \mathrm{O}$ proporcionou diferenças significativas na produtividade de colmos, açúcar e álcool (Tabela 4).

Os valores de produtividade de colmos foram elevados (média de 150,5 $\mathrm{Mg} \mathrm{ha}^{-1}$ ), o que indica o potencial de aplicação da técnica da fertirrigação na cultura da cana-de-açúcar. Essa média é 49,0\% superior à produtividade alcançada com o tratamento testemunha, de $101,0 \mathrm{Mg} \mathrm{ha}^{-1}$, que também foi elevada, tendo sido favorecida pelo adequado suprimento hídrico do solo proporcionado pela precipitação (Figura 1), bem como pela moderada fertilidade natural do solo da área experimental (Tabela 1). Em comparação à média histórica da usina (70 $\mathrm{Mg} \mathrm{ha}^{-1}$ ), a produtividade média de colmos da cana foi $115,0 \%$ superior. Produtividades elevadas de colmos sob condição irrigada, em comparação ao cultivo de sequeiro, também foram obtidas em diferentes ambientes de produção por Dantas Neto et al. (2006), Farias et al. (2008), Dalri \& Cruz (2008), Dalri et al. (2008) e Carvalho et al. (2009).

Observou-se interação significativa $(\mathrm{p}<0,05)$ entre os níveis de irrigação, de $\mathrm{N}$ e de $\mathrm{K}_{2} \mathrm{O}$ aplicados no

Tabela 3. Lâminas de irrigação e doses de $\mathrm{N}$ e $\mathrm{K}_{2} \mathrm{O}$ previstas e aplicadas no ciclo da cana-de-açúcar, primeira soca, na safra 2008/2009.

\begin{tabular}{|c|c|c|c|c|c|c|c|c|}
\hline \multirow[t]{2}{*}{ Nível $^{(1)}$} & \multicolumn{2}{|c|}{$\mathrm{W}(\mathrm{mm})$} & \multicolumn{2}{|c|}{$\mathrm{N}\left(\mathrm{kg} \mathrm{ha}^{-1}\right)$} & \multirow{2}{*}{$\begin{array}{c}\text { Ureia } \\
\left(\mathrm{kg} \mathrm{ha}^{-1}\right)\end{array}$} & \multicolumn{2}{|c|}{$\mathrm{K}_{2} \mathrm{O}\left(\mathrm{kg} \mathrm{ha}^{-1}\right)$} & \multirow{2}{*}{$\begin{array}{c}\mathrm{KCl} \\
\left(\mathrm{kg} \mathrm{ha}^{-1}\right)\end{array}$} \\
\hline & Previsto & Aplicado & Previsto & Aplicado & & Previsto & Aplicado & \\
\hline 1 & 404,0 & 288,5 & 40,0 & 44,0 & 88,9 & 40,0 & 44,0 & 73,3 \\
\hline 2 & 606,0 & 419,5 & 70,0 & 78,0 & 155,6 & 60,0 & 67,0 & 111,7 \\
\hline 3 & 808,0 & 492,0 & 100,0 & 111,0 & 246,7 & 80,0 & 89,0 & 148,3 \\
\hline 4 & $1.010,0$ & 574,0 & 130,0 & 144,0 & 320,0 & 100,0 & 111,0 & 185,0 \\
\hline 5 & $1.212,0$ & 675,0 & 160,0 & 178,0 & 395,5 & 120,0 & 133,0 & 221,7 \\
\hline Testemunha & & & 75,0 & 75,0 & 166,7 & 75,0 & 75,0 & 125,0 \\
\hline
\end{tabular}

${ }^{(1)}$ Níveis de irrigação (W) definidos como um percentual da evapotranspiração de referência (ETo): 1, 40\%; 2, 60\%; 3, 80\%; 4, 100\%; e 5, 120\%. 
ciclo da cana-de-açúcar de primeira soca, o que indica a necessidade de geração de superfícies de resposta para a avaliação do efeito integrado da aplicação dos níveis de irrigação, de $\mathrm{N}$ e de $\mathrm{K}_{2} \mathrm{O}$ na produtividade de colmos, açúcar e álcool. Para tanto, fixaram-se as lâminas de irrigação para a avaliação conjunta dos níveis de $\mathrm{N}$ e de $\mathrm{K}_{2} \mathrm{O}$ (Figura 2).

Houve incremento na produção de colmos à medida que se aumentou a aplicação de $\mathrm{N}$ e $\mathrm{K}_{2} \mathrm{O}$, até a aplicação do nível médio de irrigação (W3). A aplicação da lâmina total igual a 767,5 mm (W1) proporcionou produtividade de colmos máxima, de 149,4 $\mathrm{Mg} \mathrm{ha}^{-1}$, com os níveis ótimos de 92,2 $\mathrm{kg} \mathrm{ha}^{-1}$ de $\mathrm{N}$ e de $100,5 \mathrm{~kg} \mathrm{ha}^{-1}$ de $\mathrm{K}_{2} \mathrm{O}$ (Figura $2 \mathrm{~A}$ ). Dalri \& Cruz (2008) trabalharam com fertirrigação por gotejamento subsuperficial, em Nitossolo Vermelho transição Latossolo, textura média argilosa, com a variedade RB 72454, ciclo de primeira soca. Estes autores obtiveram produtividade de colmos da ordem de $142,2 \mathrm{Mg} \mathrm{ha}^{-1}$, com a aplicação de $60 \mathrm{~kg} \mathrm{ha}^{-1}$ de $\mathrm{N}$ e de $60 \mathrm{~kg} \mathrm{ha}^{-1}$ de $\mathrm{K}_{2} \mathrm{O}$. No entanto, os valores ótimos de $\mathrm{N}$ e $\mathrm{K}_{2} \mathrm{O}$ foram inferiores aos alcançados no presente trabalho, em virtude do nível mais elevado de

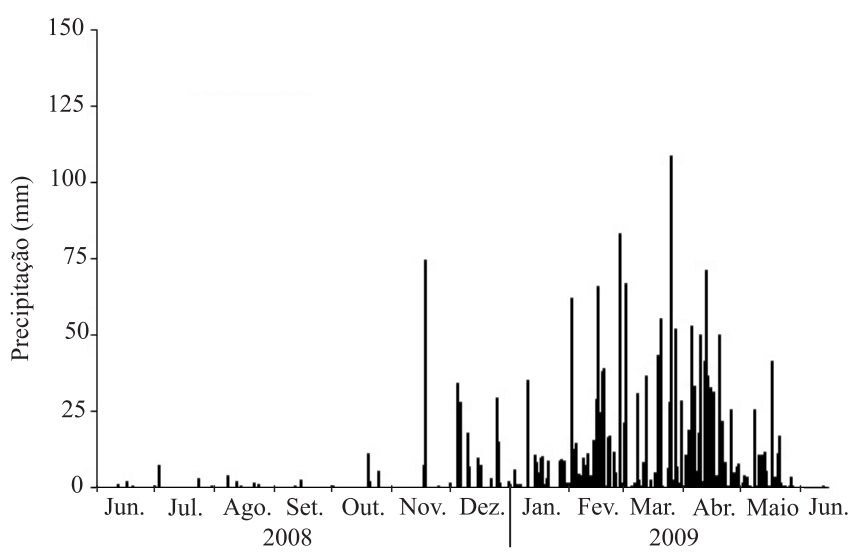

Figura 1. Distribuição da precipitação durante o ciclo da cana-de-açúcar, em ciclo de primeira soca.

Tabela 4. Produtividade de colmos em função dos níveis de irrigação (W), nitrogênio e potássio aplicados na cana-de-açúcar, em ciclo de primeira soca.

\begin{tabular}{lccccccc}
\hline Fator & \multicolumn{5}{c}{${\text { Níveis }\left(\mathrm{kg} \mathrm{ha}^{-1}\right)}$} & $\begin{array}{c}\text { Média } \\
\left(\mathrm{Mg} \mathrm{ha}^{-1}\right)\end{array}$ & $\begin{array}{c}\text { Testemunha } \\
\left(\mathrm{Mg} \mathrm{ha}^{-1}\right)\end{array}$ \\
\cline { 2 - 6 } $\mathrm{W}$ & 1 & 2 & 3 & 4 & 5 & \\
$\mathrm{~N}$ & 128,8 & 141,9 & 151,0 & 163,6 & 167,1 & 150,5 & \\
$\mathrm{~K}_{2} \mathrm{O}$ & 162,9 & 142,0 & 161,9 & 151,5 & 153,3 & 150,5 & 101,0 \\
\hline Média & 145,1 & 140,1 & 157,3 & 153,5 & 156,3 & 150,5 & \\
\hline
\end{tabular}

fertilidade natural do solo. Ao se considerar a baixa disponibilidade de água no solo, esse comportamento pode ser atribuído ao efeito residual da aplicação de $\mathrm{N}$ e de $\mathrm{K}_{2} \mathrm{O}$ do ciclo da cana-planta, o que torna o solo mais fértil e reduz a demanda de nutrientes pela cultura
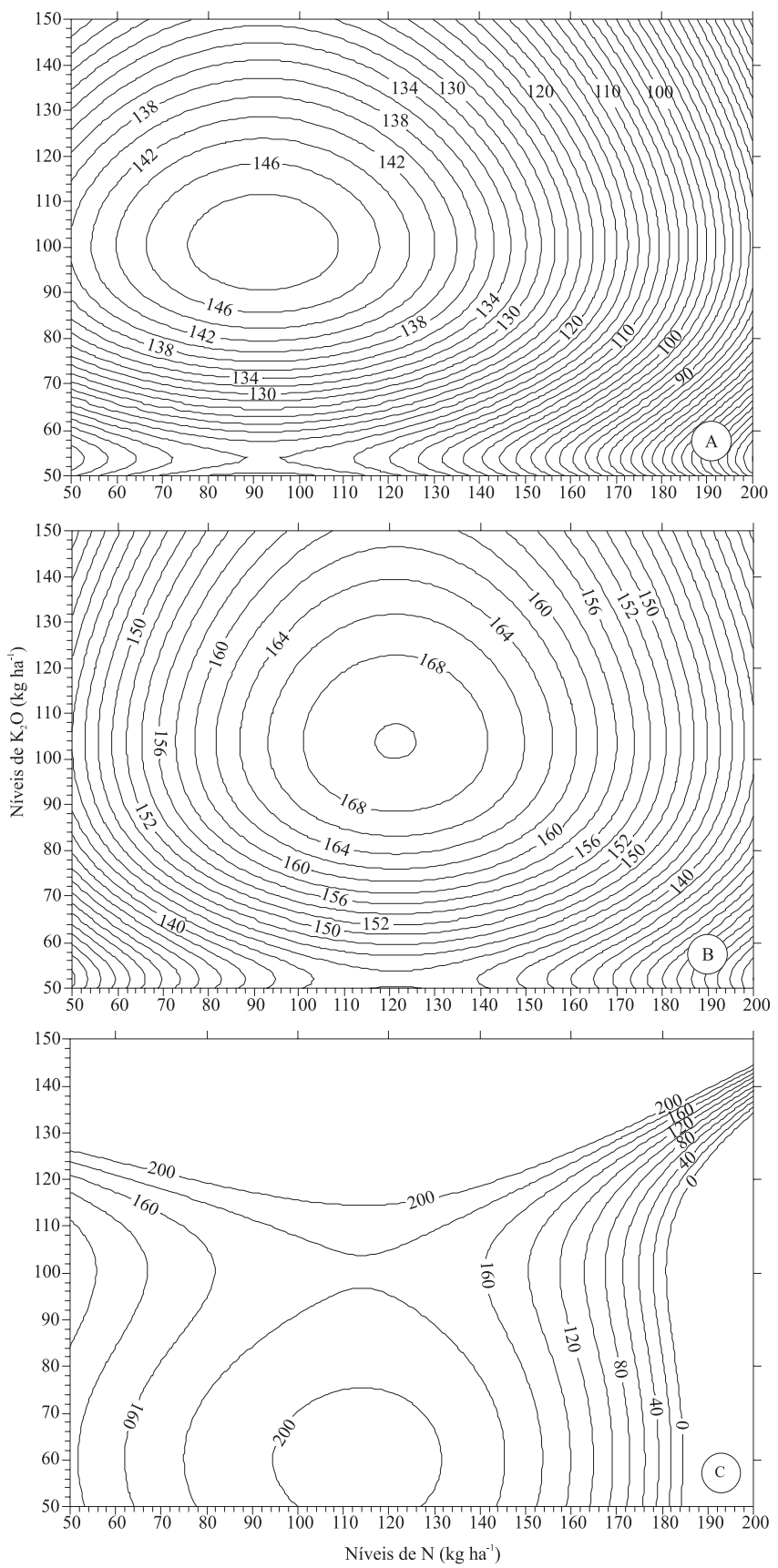

Figura 2. Superfícies de resposta da produtividade de colmos da cana-de-açúcar $\left(\mathrm{Mg} \mathrm{ha}^{-1}\right)$, em ciclo de primeira soca, com a aplicação de $\mathrm{N}$ e $\mathrm{K}_{2} \mathrm{O}$, na safra 2008/2009. A, W1; B, W3; e C, W5. 
para o alcance de níveis elevados de produtividade de colmos (Dalri \& Cruz, 2008).

Com o acréscimo na disponibilidade de água no solo proporcionado pela lâmina total igual a $971,0 \mathrm{~mm}$ (W3), a produtividade de colmos elevou-se para $170,1 \mathrm{Mg} \mathrm{ha}^{-1}$, com a aplicação de $121,3 \mathrm{~kg} \mathrm{ha}^{-1}$ de $\mathrm{N}$ e de $103,8 \mathrm{~kg} \mathrm{ha}^{-1}$ de $\mathrm{K}_{2} \mathrm{O}$ (Figura $2 \mathrm{~B}$ ). Resultados semelhantes foram obtidos por Dalri \& Cruz (2008), quando alcançaram produtividade de colmos de $171,2 \mathrm{Mg} \mathrm{ha}^{-1}$, com a aplicação de $120,0 \mathrm{~kg} \mathrm{ha}^{-1}$ de $\mathrm{N}$ e de $120 \mathrm{~kg} \mathrm{ha}^{-1}$ de $\mathrm{K}_{2} \mathrm{O}$ via fertirrigação por gotejamento subsuperficial, na variedade RB 72454, ciclo de primeira soca.

Nessa condição hídrica, os níveis ótimos de $\mathrm{N}$ e de $\mathrm{K}_{2} \mathrm{O}$ foram superiores (31,6 e 3,3\%, respectivamente) aos requeridos para o alcance da produtividade máxima de colmos, com a adoção da menor lâmina de irrigação (W1). Os níveis ótimos de nutrientes para o alcance das produtividades máximas de colmos aumentaram com o acréscimo da aplicação da lâmina de irrigação. Esse comportamento justifica-se à medida que a fertirrigação torna-se mais eficiente com o aumento da disponibilidade de água no solo, principalmente com relação aos nutrientes com elevada solubilidade, como o nitrogênio e o potássio (Dalri et al., 2008).

Quando se manteve a elevação da disponibilidade de água no solo com a aplicação da lâmina total de 1.154,0 $\mathrm{mm}$ (W5), os níveis ótimos de $\mathrm{N}$ $\left(114,2 \mathrm{~kg} \mathrm{ha}^{-1}\right)$ e de $\mathrm{K}_{2} \mathrm{O}\left(60,1 \mathrm{~kg} \mathrm{ha}^{-1}\right)$ (Figura $\left.2 \mathrm{C}\right)$ apresentaram redução de 6,2 e 72,7\%, em comparação ao nível W3. No entanto, ocorreu incremento na produtividade de colmos para 207,4 $\mathrm{Mg} \mathrm{ha}^{-1}$. Carvalho et al. (2009), ao trabalhar com irrigação pivô central e lâmina total de $1.168,0 \mathrm{~mm}$, associada a $112,0 \mathrm{~kg} \mathrm{ha}^{-1}$ de $\mathrm{N}$ e $164,0 \mathrm{~kg} \mathrm{ha}^{-1}$ de $\mathrm{K}_{2} \mathrm{O}$, com a variedade SP 791011, obtiveram produtividade máxima de colmos de $103,1 \mathrm{Mg} \mathrm{ha}^{-1}$. Este valor equivale à $50 \%$ da produtividade de colmos obtida no presente trabalho, o que reforça a ideia da melhor eficiência da aplicação de água e de nutrientes da irrigação por gotejamento, em comparação à aspersão pivô central, nas áreas de produção do Nordeste. Isso pode ser resultante da lixiviação de N e K com a aplicação da maior lâmina de irrigação, principalmente de $\mathrm{K}$, o qual é aplicado em maior proporção a partir da metade até o final do ciclo de produção (Dalri \& Cruz, 2008).
Houve incremento na produtividade de açúcar e de álcool à medida que se aumentou a aplicação de $\mathrm{N}$, notadamente, e de $\mathrm{K}_{2} \mathrm{O}$ até a aplicação do nível médio de irrigação (W3), de modo análogo ao que ocorreu com a produtividade de colmos (Figuras 3 A e 4 A). Com a aplicação da lâmina total igual a
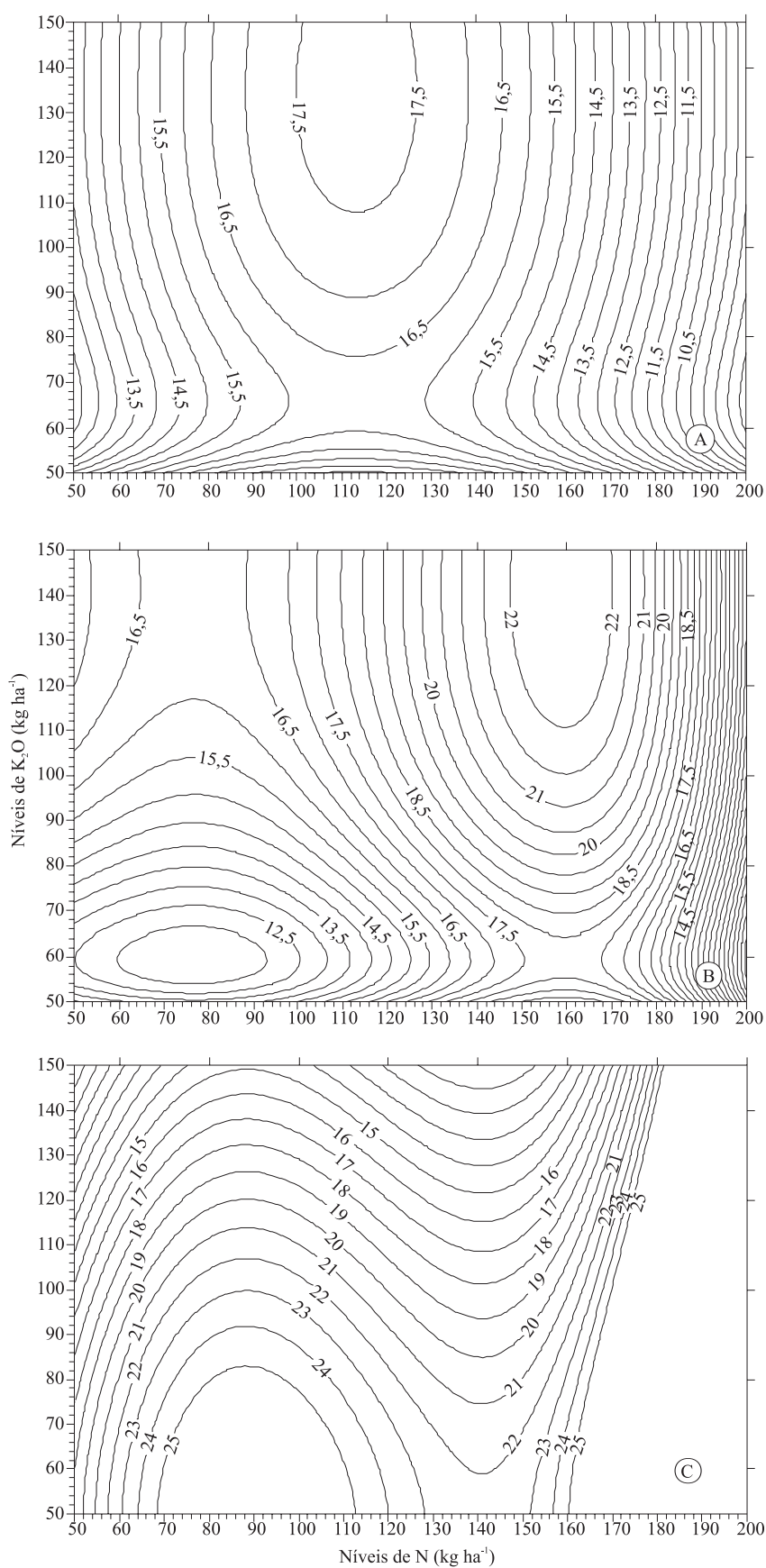

Figura 3. Superfícies de resposta da produtividade de açúcar $\left(\mathrm{Mg} \mathrm{ha}{ }^{-1}\right)$, à aplicação de $\mathrm{N}$ e $\mathrm{K}_{2} \mathrm{O}$, em cana, em ciclo de primeira soca, na safra 2008/2009. A, W1; B, W3; e C, W5. 
767,5 mm (W1), a produtividade máxima de açúcar e de álcool foi de $17,7 \mathrm{Mg} \mathrm{ha}^{-1}$ e de $12,7 \mathrm{~m}^{3} \mathrm{ha}^{-1}$, com os mesmos níveis ótimos de $113,3 \mathrm{~kg} \mathrm{ha}^{-1}$ de $\mathrm{N}$ e de $133,0 \mathrm{~kg} \mathrm{ha}^{-1} \mathrm{de}_{2} \mathrm{O}$. Dalri \& Cruz (2008) observaram produtividade de açúcar de $18,9 \mathrm{Mg} \mathrm{ha}^{-1}$, com a aplicação de $60,0 \mathrm{~kg} \mathrm{ha}^{-1}$ de $\mathrm{N}$ e de $60 \mathrm{~kg} \mathrm{ha}^{-1}$ de $\mathrm{K}_{2} \mathrm{O}$ via fertirrigação por gotejamento subsuperficial, na variedade RB 72454, ciclo de primeira soca. Portanto, estes autores obtiveram praticamente a mesma produtividade de açúcar quando aplicaram metade dos níveis máximos definidos no presente trabalho. Isso, provavelmente, resultou do elevado nível de fertilidade natural do solo e do potencial produtivo distinto das variedades avaliadas nos experimentos.

Quanto à produtividade de álcool, o valor máximo de $12,7 \mathrm{~m}^{3}$ ha $^{-1}$ foi $17,6 \%$ superior aos valores alcançados em outros estudos. Moura et al. (2005), ao avaliar a cultivar SP 791011, nos Tabuleiros Costeiros da Paraíba, sob irrigação pivô central, obtiveram valor máximo de $10,8 \mathrm{~m}^{3} \mathrm{ha}^{-1}$ de álcool, com a aplicação de $955,1 \mathrm{~mm}$. Isso indica que, com a aplicação de lâmina total inferior de $767,5 \mathrm{~mm}$ e gotejamento subsuperficial, que aplica água com maior eficiência que o pivô central, foi possível obter produção superior de álcool com menor quantidade de água.

Com o acréscimo na disponibilidade de água no solo proporcionado pela lâmina total de $971,0 \mathrm{~mm}$ (W3), a produtividade de açúcar e de álcool elevouse para 22,5 $\mathrm{Mg} \mathrm{ha}^{-1}$ e $16,0 \mathrm{~m}^{3} \mathrm{ha}^{-1}$, respectivamente, com a aplicação dos níveis de $160,0 \mathrm{~kg} \mathrm{ha}^{-1}$ de $\mathrm{N}$ e 133,0 $\mathrm{kg} \mathrm{ha}^{-1}$ de $\mathrm{K}_{2} \mathrm{O}$ (Figuras $3 \mathrm{~B}$ e $4 \mathrm{~B}$ ). Resultados semelhantes foram obtidos por Dalri \& Cruz (2008), que observaram produtividade de açúcar de $21,7 \mathrm{Mg}$ ha $^{-1}$, com a aplicação de $120,0 \mathrm{~kg} \mathrm{ha}^{-1}$ de $\mathrm{N}$ e de $120 \mathrm{~kg} \mathrm{ha}^{-1}$ de $\mathrm{K}_{2} \mathrm{O}$ via fertirrigação por gotejamento subsuperficial, na variedade RB 72454, ciclo de primeira soca. A lâmina de irrigação aplicada foi de 520,0 mm, próxima da lâmina W3, de 492,0 mm (Tabela 3), aplicada no presente trabalho.

Com a aplicação da lâmina total, mais elevada, de 1.154,0 mm (W5), os níveis ótimos de $\mathrm{N}\left(90,0 \mathrm{~kg} \mathrm{ha}^{-1}\right)$ e de $\mathrm{K}_{2} \mathrm{O}\left(60,0 \mathrm{~kg} \mathrm{ha}^{-1}\right)$ reduziram-se, em comparação ao nível W3 (Figuras $3 \mathrm{C}$ e $4 \mathrm{C}$ ). Entretanto, ocorreu ligeiro incremento na produtividade de açúcar $(25,3 \mathrm{Mg}$ $\left.\mathrm{ha}^{-1}\right)$ e de álcool $\left(20,0 \mathrm{~m}^{3} \mathrm{ha}^{-1}\right)$. Esse comportamento foi idêntico ao observado para produtividade de colmos (Figura 3) e pode ser atribuído à lixiviação de $\mathrm{N}$ e K, com a aplicação da maior lâmina de irrigação, especialmente de $\mathrm{K}$, que é aplicado em maior proporção da metade para o final do ciclo de produção. É importante ressaltar que a produtividade de açúcar e de álcool está estritamente relacionada à produtividade de colmos e à qualidade tecnológica do caldo obtido, principalmente quanto aos valores de PCC (Tabela 5),
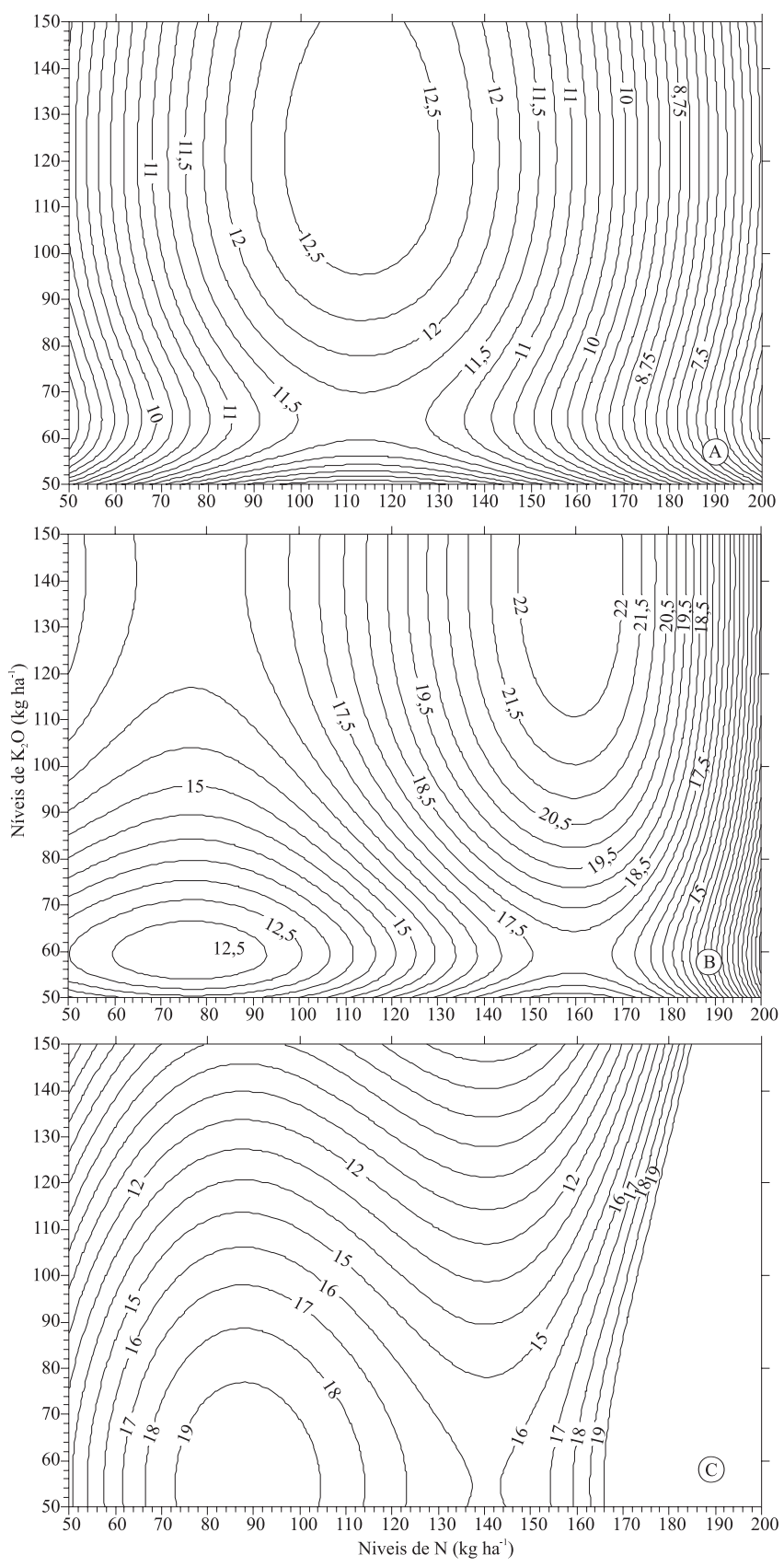

Figura 4. Superfícies de resposta da produtividade de álcool $\left(\mathrm{m}^{3} \mathrm{ha}^{-1}\right)$, à aplicação de $\mathrm{N}$ e $\mathrm{K}_{2} \mathrm{O}$, em cana, em ciclo de primeira soca, na safra 2008/2009. A, W1; B, W3; e C, W5. 
com os níveis de irrigação, de $\mathrm{N}$ e de $\mathrm{K}_{2} \mathrm{O}$, conforme apresentado nas equações 1 e 2 .

Ao se considerar a mesma disponibilidade de água no solo (W1 e W3), os níveis ótimos de $\mathrm{N}$ e de $\mathrm{K}_{2} \mathrm{O}$, que proporcionaram as máximas produtividades de açúcar e de álcool, foram superiores aos que possibilitaram a máxima produtividade de colmos. Isso ocorreu porque, sob baixa (W1) e média (W3) disponibilidade de água no solo, a qualidade tecnológica do caldo foi superior com a aplicação de doses maiores de $\mathrm{N}$ e de $\mathrm{K}_{2} \mathrm{O}$ (Tabela 5), uma vez que a lixiviação desses nutrientes, provavelmente, foi reduzida sob essa condição hídrica no solo. Com a elevação da disponibilidade de água no solo, ocasionada com a aplicação da maior lâmina de irrigação (W5), é possível que o processo de lixiviação desses nutrientes tenha sido maior, o que reduziu a sua contribuição para a qualidade tecnológica do caldo. Ressalta-se que o potássio tem papel fundamental na qualidade tecnológica do caldo, sobretudo no que diz respeito ao conteúdo de açúcares totais (Uchôa et al., 2009). Portanto, nessa condição hídrica, o pequeno acréscimo ocorrido na produtividade de açúcar e álcool, em comparação à obtida com a lâmina W3, foi resultante mais do maior volume de produção de colmos do que da qualidade tecnológica do caldo (Carvalho et al., 2009).

Comparativamente ao tratamento testemunha, que recebeu, em cobertura, o equivalente a $75 \mathrm{~kg} \mathrm{ha}^{-1}$ de $\mathrm{N}$ e $75 \mathrm{~kg} \mathrm{ha}^{-1}$ de $\mathrm{K}_{2} \mathrm{O}$, o tratamento irrigado com a menor lâmina (W1) produziu $50 \%$ de açúcar e 49,4\% de álcool a mais por hectare, mesmo tendo recebido, em fertirrigação, dose de $\mathrm{N}$ e de $\mathrm{K}_{2} \mathrm{O} 33$ e $60 \%$ superior, respectivamente (Tabela 5). Isso indica a existência da viabilidade técnica da prática da irrigação e da fertirrigação da cana-de-açúcar, mas que precisa ser comprovada em termos econômicos, em estudos futuros.

Tabela 5. Valores máximos de percentagem da açúcar bruto (PCC) e respectivas produtividades de colmo (PC), açúcar (PA) e álcool (VA), obtidos com a aplicação de níveis de $\mathrm{N}$ e $\mathrm{K}_{2} \mathrm{O}$, em cada lâmina de irrigação (W), na safra 2008/2009.

\begin{tabular}{lcccccc}
\hline $\begin{array}{l}\text { W } \\
(\mathrm{mm})\end{array}$ & $\begin{array}{c}\mathrm{N} \\
-----\left(\mathrm{kg} \mathrm{ha}^{-1}\right)-----\end{array}$ & $\begin{array}{c}\text { PCC } \\
(\%)\end{array}$ & $\begin{array}{c}\text { PC } \\
-----\left(\mathrm{Mg} \mathrm{ha}^{-1}\right)-----\end{array}$ & $\begin{array}{c}\text { PA } \\
\left(\mathrm{m}^{3} \mathrm{ha}^{-1}\right)\end{array}$ \\
\hline 289 & 100 & 120 & 12,7 & 138,2 & 17,7 & 12,7 \\
492 & 130 & 120 & 13,3 & 163,1 & 21,7 & 15,5 \\
675 & 100 & 40 & 12,8 & 198,5 & 25,2 & 18,1 \\
Testemunha & 75 & 75 & 11,6 & 101,0 & 11,8 & 8,5 \\
\hline
\end{tabular}

\section{Conclusões}

1. A máxima produtividade de colmos $(207,4 \mathrm{Mg}$ ha $^{-1}$ ) é obtida com a aplicação de lâmina total de água (chuva mais irrigação) de 1.154,0 mm e com a aplicação de $114,2 \mathrm{~kg} \mathrm{ha}^{-1}$ de $\mathrm{N}$ e $60,1 \mathrm{~kg} \mathrm{ha}^{-1}$ de $\mathrm{K}_{2} \mathrm{O}$.

2. A máxima produtividade de açúcar $\left(25,3 \mathrm{Mg} \mathrm{ha}^{-1}\right)$ e de álcool $\left(20,0 \mathrm{~m}^{3}\right.$ ha $\left.^{-1}\right)$ é obtida com a aplicação de lâmina total de água (chuva mais irrigação) de $1.154,0 \mathrm{~mm}$ e com a aplicação de $90,0 \mathrm{~kg} \mathrm{ha}^{-1}$ de $\mathrm{N}$ e de $60,0 \mathrm{~kg} \mathrm{ha}^{-1}$ de $\mathrm{K}_{2} \mathrm{O}$.

\section{Referências}

ANDRADE JÚNIOR, A.S. de; BASTOS, E.A.; SILVA, C.O. da; GOMES, A.A.N.; FIGUEREDO JÚNIOR, L.G.M. de. Atlas climatológico do Estado do Piauí. Teresina: Embrapa Meio-Norte, 2004. 151p. (Embrapa Meio-Norte. Documentos, 101).

BASTOS, E.A.; ANDRADE JÚNIOR, A.S. de; RODRIGUES, B.H.N. Boletim agrometeorológico de 2007 para o Município de Teresina, Piauí. Teresina: Embrapa Meio-Norte, 2008. 37p. (Embrapa Meio-Norte. Documentos, 181).

CALDAS, C. Manual de análises selecionadas para indústrias sucroalcooleiras. Maceió: Sindicato da Indústria e do Álcool do Estado de Alagoas, 1998. 424p.

CARVALHO, C.M. de; AZEVEDO, H.M. de; DANTAS NETO, J.; FARIAS, C.H. de A.; SILVA, C.T.S.; GOMES FILHO, R.R. Rendimento de açúcar e álcool da cana-de-açúcar submetida a diferentes níveis de irrigação. Revista Brasileira de Ciências Agrárias, v.4, p.72-77, 2009.

COMPANHIA NACIONAL DE ABASTECIMENTO. Acompanhamento de safra brasileira: cana-de-açúcar: primeiro levantamento: maio 2011. Brasília: Conab, 2011. 19p.

DALRI, A.B.; CRUZ, R.L. Efeito da freqüência de irrigação subsuperficial por gotejamento no desenvolvimento da cana-de-açúcar (Saccharum spp.). Irriga, v.7, p.29-34, 2002.

DALRI, A.B.; CRUZ, R.L. Produtividade da cana-de-açúcar fertirrigada com $\mathrm{N}$ e K via gotejamento subsuperficial. Engenharia Agrícola, v.28, p.516-524, 2008.

DALRI, A.B.; CRUZ, R.L.; GARCIA, C.J.B.; DUENHAS, L.H. Irrigação por gotejamento subsuperficial na produção e qualidade de cana-de-açúcar. Irriga, v.13, p.1-11, 2008.

DANTAS NETO, J.; FIGUEREDO, J.L. da C.; FARIAS, C.H. de A.; AZEVEDO, H.M.; AZEVEDO, C.A.V. de. Resposta da cana-de-açúcar, primeira soca, a níveis de irrigação e adubação de cobertura. Revista Brasileira de Engenharia Agrícola e Ambiental, v.10, p.283-288, 2006.

FARIAS, C.H. de A.; FERNANDES, P.D.; AZEVEDO, H.M.; DANTAS NETO, J. Índices de crescimento da cana-de-açúcar irrigada e de sequeiro no Estado da Paraíba. Revista Brasileira de Engenharia Agrícola e Ambiental, v.12, p.356-362, 2008. 
MANZATTO, C.V.; ASSAD, E.D.; BACCA, J.F.M.; ZARONI, M.J.; PEREIRA, S.E.M. Zoneamento agroecológico da cana-de-açúcar: expandir a produção, preservar a vida, garantir o futuro. Rio de Janeiro: Embrapa Solos, 2009. 55p. (Embrapa Solos. Documentos, 110).

MINISTÉRIO DA AGRICULTURA, PECUÁRIA E ABASTECIMENTO. Plano Nacional de Agroenergia 2006-2011. Brasília: MAPA, 2008. 118p.

MOURA, M.V.P. da S.; FARIAS, C.H. de A.; AZEVEDO, C.A.V. de; DANTAS NETO, J.; AZEVEDO, H.M. de; PORDEUS, R.V. Doses de adubação nitrogenada e potássica em cobertura na cultura da cana-de-açúcar, primeira soca, com e sem irrigação. Ciência Agrotécnica, v.29, p.753-760, 2005.
SANTOS, H.G. dos; JACOMINE, P.K.T.; ANJOS, L.H.C. dos; OLIVEIRA, V.A. de; OLIVEIRA, J.B. de; COELHO, M.R.; LUMBRERAS, J.F.; CUNHA, T.J.F. (Ed.). Sistema brasileiro de classificação de solos. 2.ed. Rio de Janeiro: Embrapa Solos, 2006. $306 \mathrm{p}$.

SAS INSTITUTE. SAS/STAT: user's guide. Version 8.1.Cary: SAS Institute, 2000. 943p.

THORNTHWAITE, C.W.; MATHER, J.R. The water balance. New Jersey: Centerton, 1955. 104p.

UCHÔA, S.C.P.; ALVES JUNIOR, H. de O.; ALVES, J.M.A.; MELO, V.F.; FERREIRA, G.B. Resposta de seis variedades de cana-de-açúcar a doses de potássio em ecossistema de cerrado de Roraima. Revista Ciência Agronômica, v.40, p.505-513, 2009.

Recebido em 19 de agosto de 2011 e aprovado em 7 de dezembro de 2011 